\title{
ANALISIS FAKTOR PERILAKU KEUANGAN TERHADAP KEPUTUSAN INVESTASI EMAS MASYARAKAT KOTA BATAM
}

\author{
Johny Budiman dan Jasika \\ ${ }^{1)}$ Program Studi Manajemen, Universitas Internasional Batam \\ Jl Gajah Mada, Baloi Sei Ladi Batam 29442 \\ email: Johny.budiman@uib.ac.id \\ ${ }^{2)}$ Program Studi Manajemen, Universitas Internasional Batam \\ Jl Gajah Mada, Baloi Sei Ladi Batam 29442 \\ email: jasika.chika@yahoo.com
}

\begin{abstract}
The purpose of this study is to investigate the influence of behavioral factors which consisting of regret aversion, overconfidence, loss aversion, heuristics and availability bias on gold investment decisions in Batam City investor. To conduct the study, a total of 250 questionnaires were issued and distributed to the investors of gold in Batam city. To test the hypothesis, multiple linear reggression analysis is used. The results of the research showed that regret aversion has a significant and positive effect and loss aversion has a negative significant influence on gold investment decisions. While there are no significant influence of overconfidence, heuristic and availability bias to investment decisions.
\end{abstract}

Keyword: investment decision, regret aversion, overconfidence, loss aversion, heuristic, availability bias.

\begin{abstract}
Abstrak
Tujuan dari penelitian ini adalah untuk mengetahui pengaruh faktor perilaku yang terdiri dari keengganan penyesalan, terlalu percaya diri, keengganan kerugian, heuristik dan bias ketersediaan pada keputusan investasi emas di investor Kota Batam. Untuk melakukan penelitian, total 250 kuesioner dikeluarkan dan didistribusikan kepada investor emas di kota Batam. Untuk menguji hipotesis, digunakan analisis regresi linier berganda. Hasil penelitian menunjukkan bahwa penyesalan penyesalan memiliki pengaruh signifikan dan positif dan keengganan kerugian memiliki pengaruh negatif signifikan terhadap keputusan investasi emas. Meskipun tidak ada pengaruh signifikan dari kepercayaan yang berlebihan, heuristik dan bias ketersediaan terhadap keputusan investasi.
\end{abstract}

Kata Kunci: Keputusan Investasi, Kepercayaan Diri, Penolakan, Heuristik, Bias Ketersediaan.

\section{PENDAHULUAN}

Pertumbuhan ekonomi Indonesia melambat dikarenakan kondisi ekonomi yang tidak menentu ditandai dengan rupiah terus melemah terhadap dollar Amerika Serikat, pelemahan nilai mata uang Rupiah menyebabkan meningkatnya harga barang atau jasa. Hal ini semakin parah dengan mayoritas penduduk Indonesia yang berada pada kelas menengah ke bawah sehingga semakin menurunkan daya minat dan daya beli masyarakat. Akibat kondisi nilai tukar mata uang dollar Amerika Serikat terhadap Rupiah yang tidak menentu, maka harga emas juga mengalami fluktuasi. Peningkatan dan penurunan harga emas di Indonesia dalam kurun waktu 2017 -2018 dapat dilihat dari Gambar1 di bawah ini:

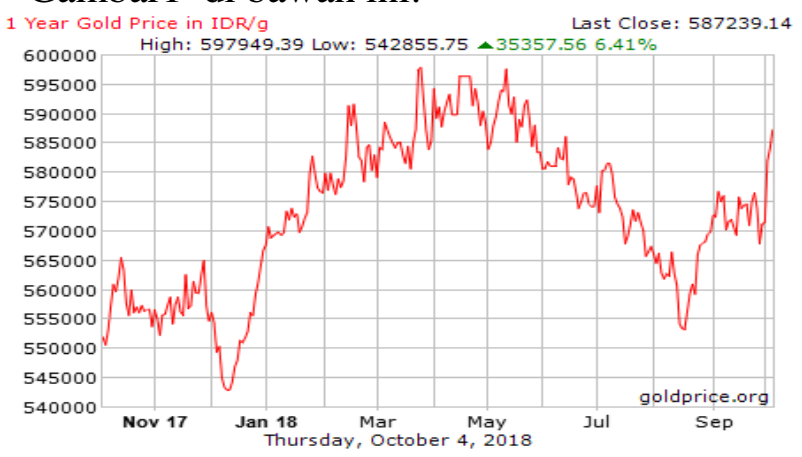

Gambarl. Harga emas dari November 2017September 2018, sumber: hargaindo.com (2018) 
Pada tahun 2018, pertumbuhan ekonomi di Indonesia disebut-sebut lebih optimistis, namun di tengah pertumbuhan ekonomi, masyarakat Indonesia perlu bersikap waspada dengan anomali ekonomi. Salah satu langkah untuk mengantisipasi anomali ekonomi adalah dengan mengembangkan dana tabungan dan investasi. Hasil riset pemasaran Inside ID mencatat, $50 \%$ dari 224 responden di Indonesia memilih emas sebagai instrumen investasi dan sisanya memilih deposito, properti, reksadana dan saham.

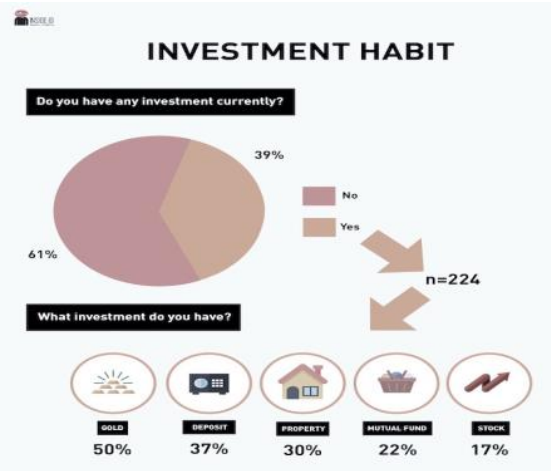

Gambar2. Hasil riset dari 224 responden, sumber: marketeers.com (2018)

Namun masalah sering timbul dalam melakukan investasi emas seperti belum memahami dengan benar tentang standar perhitungan harga emas yang berlaku, sehingga hasil yang didapat kurang maksimal pada saat melakukan penjualan. Beberapa kasus penipuan yang didapat oleh investor emas adalah kasus CV Kebun Emas Indonesia (2017), kasus Raihan Jewelly (2013), kasus Golden Traders Indonesia Syariah (2012), Virgin Gold Mining Corporation (2013) yang rata-rata menjanjikan keuntungan diatas kewajaran yaitu sebesar lima persen sebulan dan akhirnya kabur membawa uang investornya (Money Smart, 2018).

Keputusan investasi merupakan suatu keputusan yang akan diterima dimasa yang akan datang dengan menaruh modal pada satu aset atau lebih, yang bertujuan untuk memperoleh beberapa keuntungan. Pengalaman dalam berinvestasi akan mempengaruhi keputusan investasi sehingga seorang investor harus memiliki pengetahuan dasar mengenai keuangan dan cara untuk mengaplikasikan pengetahuan tersebut dengan sikap yang dimilikinya.

Tujuan penelitian ini adalah untuk mengetahui faktor-faktor perilaku keuangan yang berpengaruh terhadap keputusan investasi emas masyarakat kota Batam. Faktor-faktor perilaku keuangan yang digunakan dalam penelitian ini adalah regret aversion, overconfidence, loss aversion, heuristics and availability bias.

Regret Aversion adalah keputusan untuk menghindari kesalahan pada keputusan investasi yang sama karena merasa takut untuk menghadapi kerugian yang sama didalam diri seseorang (Yohnson, 2008). Hal ini menyebabkan seseorang atau investor akan terlalu lama untuk mempertahankan sebuah instrumen yang seharusnya mereka sudah mendapatkan keuntungan dari investasinya. Hasil penelitian Velumoni (2017) dan Grover dan Singh (2015), menunjukkan bahwa adanya hubungan signifikan positif antara regret aversion terhadap keputusan investasi. denganmempertahankan investasi pada waktu tertentu akan mendapatkan keuntungan bahkan dengan jangka waktu yang lebih panjang akan mendapatkan keuntungan yang lebih besar lagi. Namun, hasil penelitian Talha et al. (2015) dan Chitra dan Jayashree (2014), menunjukkan tidak adanya pengaruh signifikan antara regret aversion terhadap keputusan investasi, karena investor ingin menghasilkan return tinggi dengan jangka waktu yang pendek sehingga regret diabaikan.

Overconfidence adalah perilaku seseorang yang terlalu percaya diri. Dan biasanya kecenderungan untuk mengadaada terhadap pengetahuan yang dimiliki, menyepelekan risiko dan melebihlebihkan kemampuannya untuk mengelola peristiwa yang terjadi. Hasil penelitian Bakar dan Yi (2016), Qadri dan Shabbir (2014), Bashir et al. (2013), Antony dan Joseph (2017), Rostami dan Dehaghani 
(2015), Khan et al. (2017), Talha et al. (2015) dan Chitra dan Jayashree (2014), menunjukkan bahwa adanya hubungan signifikan positif antara overconfidence terhadap keputusan investasi. Dengan terlalu percaya diri, mampu memprediksi keadaan pasar dan mendapatkan keuntungan yang besar atas investasi yang mereka lakukan. Namun, Sadi et al. (2010), menyatakan bahwa tidak ada pengaruh yang signifikan antara overconfidence terhadap keputusan investasi, karena kepercayaan diri dari seorang memiliki sudut pandang yang berbeda-beda sehingga tidak mempengaruhi harga emas yang cenderung fluktuatif.

Loss Aversion adalah kecendrungan mempertimbangkan kerugian yang lebih besar daripada keuntungan yang serupa dalam keputusan investasi. Seseorang yang melakukan investasi akan lebih memikirkan untuk menghindari kerugian daripada memikirkan untuk mendapatkan keuntungan. Apabila nilai investasi mereka mengalami penurunan, mereka akan lebih memilih untuk tetap mempertahankan investasinya dengan harapan akan mengalami peningkatan nilai dimasa depan. Hasil penelitian Rostami dan Dehaghani (2015), Khan (2015), Khan, et al. (2017) dan Velumoni (2017), menunjukkan bahwa adanya hubungan signifikan positif antara loss aversion terhadap keputusan investasi. Investor yang pernah mengalami kerugian terhadap investasi yang mereka lakukan, akan menghindari kerugian daripada mendapatkan keuntungan. Namun hasil penelitian Bashir et al. (2013) dan Talha et al. (2015), menunjukkan bahwa adanya pengaruh signifikan negatif antara loss aversion terhadap keputusan investasi, karena investor belum pernah mengalami kerugian terhadap investasi yang mereka lakukan, dan mempunyai anggapan bahwa investasi selalu untung dan tidak pernah rugi.

Heuristic adalah seseorang yang berpikir bahwa menyelesaikan suatu masalah dengan cara mencari, menemukan, mengumpulkan sumbersumber dari berbagai data yang berhubungan dengan kejadian di masa lalu. Heuristic juga berguna untuk meringankan upaya kognitif supaya dalam pengambilan keputusan juga menjadi lebih mudah, sehingga tidak membutuhkan banyak waktu. Hasil studi Charles dan Kasilingam (2016), Kimeu et al. (2016) dan Farooq et al. (2015), menunjukkan bahwa adanya hubungan signifikan positif antara keputusan investasi dengan heuristic, karenat memiliki wawasan dan pemahaman yang baik untuk membuat keputusan investasi. Namun, Kengatharan dan Kengatharan (2014), menunjukkan tidak ada pengaruh signifikan antara keputusan investasi dengan heuristic, karena ada kejadian dan perubahan yang tidak dapat diperkirakan sehingga tidak semua kondisi bisa dihadapai dengan perlakuan yang sama, seperti nilai tukar emas, penguatan atau pelemahan mata uang, anomali ekonomi, dan lain lain.

Availability Bias adalah kecenderungan seseorang menganggap kejadian yang mudah diingat lebih representatif daripada yang jarang mereka bayangkan atau rasakan dan mereka bertindak berdasarkan informasi terkini yang diperoleh. Penelitian Bakar dan Yi (2016) dan Sadi et al. (2010), menunjukkan bahwa adanya hubungan signifikan positif antara keputusan investasi dengan availability bias, karena investor memilih peristiwa yang lebih gampang diingat. Namun penelitian Khan (2015) bertolak belakang yang menunjukkan tidak ada pengaruh signifikan antara keputusan investasi dengan availability bias, karena investor tertinggal dengan beberapa informasi pasar terhadap nilai tukar emas dikarenakan perubahan nilai tukar emas cukup signifikan dan cepat, bahkan setiap jam harga emas bisa berubah.

Berdasarkan tinjauan pustaka terdahulu, maka hipotesis penelitian adalah sebagai berikut: 
$\mathrm{H}_{1}$ : Regret Aversion berpengaruh signifikan positif terhadap keputusan investasi emas masyarakat kota Batam.

$\mathrm{H}_{2}$ : Overconfidence berpengaruh signifikan positif terhadap keputusan investasi emas masyarakat kota Batam.

$\mathrm{H}_{3}$ : Loss Aversion Bias berpengaruh signifikan negatif terhadap keputusan investasi emas masyarakat kota Batam.

$\mathrm{H}_{4}$ : Heuristics berpengaruh signifikan positif terhadap keputusan investasi emas masyarakat kota Batam.

$\mathrm{H}_{5}$ : Availability bias berpengaruh signifikan positif terhadap keputusan investasi emas masyarakat kota Batam.

\section{METODE PENELITIAN}

Penelitian ini merupakan penelitian kuantitatif dengan data primer, dimana data primer dikumpulkan melalui kuesioner google form. Variabel yang akan diteliti yaitu pengaruh dari regret aversion, overconfidence, loss aversion, heuristics dan availability bias, terhadap keputusan investasi emas . Metode nonprobabilitas merupakan metode yang digunakan oleh peneliti dalam menentukan sampel yang dibutuhkan dalam penelitian yang berupa judgmental sampling, yang di mana sampel yang diteliti memiliki kesesuaian kriteria tertentu. Kuesioner dibagikan baik secara langsung maupun dengan mengisi google form kepada investor emas di kota Batam.

Objek penelitian yang digunakan adalah masyarakat kota Batam yang berinvestasi emas. Metode Hair et al. (2010) digunakan untuk menentukan jumlah sample. Jumlah kuesioner yang dibagikan kepada investor emas di Kota Batam berjumlah 19 kuesioner, sehingga diperoleh jumlah sampel minimal 95 responden. Untuk menghindari adanya data kuesioner yang rusak, tidak kembali, dan tidak diisi lengkap serta untuk menghindari pengurangan data pada pengujian outlier, maka jumlah sampel ditentukan sebanyak 250 responden.

Skala yang digunakan adalah skala likert yang menunjukkan lima poin yang terdiri dari 1 (sangat tidak setuju), 2 (tidak setuju), 5 (netral ), 4 (setuju), dan 5 (sangat setuju). Analisis data dan uji hipotesis dilakukan dengan regresi liniar berganda untuk memprediksi pengaruh variabel bebas terhadap keputusan investasi emas.

\section{HASIL DAN PEMBAHASAN}

\section{Uji F}

Model regresi dapat dipakai dalam menjelaskan keputusan investasi emas dengan hasil dari uji F/ ANOVA sebesar $0,019<0,05$.

Tabel Hasil Uji F

\begin{tabular}{ccc}
\hline Model & Sig. & Keterangan \\
\hline Regression Residual & $0.019^{\mathrm{a}}$ & Signifikan \\
\hline Sumber: Data primer diolah $(2019)$ &
\end{tabular}

Hasil uji t terdapat pada tabel di bawah ini:

Tabel Hasil Uji t

\begin{tabular}{|c|c|c|c|}
\hline Variabel & Sig & $\boldsymbol{B}$ & Kesimpulan \\
\hline $\begin{array}{l}\text { Regret } \\
\text { Aversion }\end{array}$ & 0,001 & 0,371 & $\begin{array}{l}\text { Hipotesis } \\
\text { diterima }\end{array}$ \\
\hline $\begin{array}{l}\text { Overconfidenc } \\
\mathrm{e}\end{array}$ & 0,825 & $-0,017$ & Hipotesis ditolak \\
\hline Loss Aversion & 0,048 & $-0,183$ & $\begin{array}{l}\text { Hipotesis } \\
\text { diterima }\end{array}$ \\
\hline Heuristic & 0,056 & 0,174 & Hipotesis ditolak \\
\hline $\begin{array}{l}\text { Availability } \\
\text { Bias }\end{array}$ & 0,634 & 0,031 & Hipotesis ditolak \\
\hline
\end{tabular}

Sumber: Data primer diolah (2019)

Berdasarkan hasil yang didapat dari penelitian ini pengaruh regret aversion terhadap keputusan investasi emas pada masyarakat Kota Batam, hasil nilai t dari regret aversion adalah sebesar 0,371 dengan tingkat signifikansi sebesar 0,001, artinya memiliki pengaruh yang signifikan dan arah yang positif. Hal ini dikarenakan responden lebih lama mempertahankan harga investasi emas yang mereka miliki sehingga responden mendapatkan 
keuntungan dengan jangka waktu yang lebih panjang. Hasil penelitian ini konsiten dengan penelitian yang dilakukan oleh Velumoni (2017) dan Grover dan Singh (2015) yang menyimpulkan bahwa pengaruh regret aversion terhadap keputusan investasi adalah signifikan positif.

Pengaruh overconfidence terhadap keputusan investasi emas pada masyarakat Kota Batam, dengan nilai sebesar $-0,017$ dan tingkat signifikansi sebesar 0,825. Berdasarkan nilai tersebut dapat disimpulkan bahwa overconfidence tidak berpengaruh terhadap keputusan investasi emas pada masyarakat Kota Batam. Hal ini dikarenakan kepercayaan diri dari seorang responden memiliki sudut pandang yang berbeda-beda sehingga tidak mempengaruhi harga emas yang cendrung fluktuatif. Hasil penelitian ini dengan penelitian yang dilakukan oleh Sadi et al. (2010) yang menyimpulkan bahwa overconfidence tidak berpengaruh terhadap keputusan investasi. Namun bertolak belakang dengan hasil penelitian Bakar dan Yi (2016), Qadri dan Shabbir (2014), Bashir et al. (2013), Antony dan Joseph (2017), Rostami dan Dehaghani (2015), Khan et al. (2017), Talha et al. (2015) dan Chitra dan Jayashree (2014) yang menjukkan pengaruh signifikan positif terhadap keputusan investasi.

Nilai $\mathrm{t}$ dari loss aversion adalah sebesar -0,183 dengan tingkat signifikansi sebesar 0,048. Berdasarkan nilai tersebut dapat disimpulkan bahwa pengaruh dari loss aversion terhadap keputusan investasi emas pada masyarakat Kota Batam memiliki pengaruh signifikan negatif. Hal ini dikarenakan responden yang melakukan investasi emas belum pernah mengalami kerugian sehingga mereka berpikiran investasi emas selalu untung dan tidak pernah rugi. Hasil penelitian ini konsisten penelitian yang dilakukan oleh Bashir et al. (2013) dan Talha et al. (2015) yang menyimpulkan bahwa pengaruh loss aversion terhadap keputusan investasi adalah signifikan negatif. Namun bertolak belakang dengan penelitian Rostami dan Dehaghani (2015), Khan (2015), Khan, et al. (2017) dan Velumoni (2017) loss aversion berpengaruh signifikan positif terhadap keputusan investasi.

Nilai t dari heuristic adalah sebesar 0,174 dengan tingkat signifikansi sebesar 0,056. dapat disimpulkan bahwa heuristic tidak berpengaruh terhadap keputusan investasi emas. Hal ini dikarenakan ada kejadian dan perubahan yang tidak dapat diperkirakan sehingga tidak semua kondisi bisa dihadapai dengan perlakuan yang sama, seperti nilai tukar emas, penguatan atau pelemahan mata uang, anomali ekonomi, dan lain lain. Hasil penelitian ini sesuai terhadap penelitian yang dilakukan oleh Kengatharan dan Kengatharan (2016), yang menyimpulkan bahwa heuristic tidak berpengaruh terhadap keputusan investasi. Akan tetapi bertolak belakang dengan penelitianyang dilakukan oleh Charles dan Kasilingam (2016), Kimeu et al. (2016) dan Farooq et al. (2015) yang berpengaruh signifikan positif terhadap keputusan investasi.

Hasil uji t dari availability bias adalah sebesar 0,031 dengan tingkat signifikansi sebesar 0,634. Dapat disimpulkan bahwa availability bias tidak berpengaruh terhadap keputusan investasiemas pada masyarakat Kota Batam. Hal ini dikarenakan responden tertinggal dengan beberapa informasi pasar terhadap nilai tukar emas dikarenakan perubahan nilai tukar emas cukup signifikan dan cepat, bahkan setiap jam harga emas bisa berubah. Hasil penelitian ini sejalan dengan penelitian yang dilakukan oleh Khan (2015) yang menyimpulkan bahwa availability bias tidak berpengaruh terhadap keputusan investasi. Namun bertolak belakang dengan penelitian Bakar dan Yi (2016) dan Sadi et al. (2010), yang mempunyai pengaruh signifikan positif terhadap keputusan investasi.

\section{Uji Koefisien Determinasi $\left(\mathbf{R}^{2}\right)$}

Nilai koefisiensi determinasi terhadap keputusan investasi emas adalah sebesar 
0,059. Artinya sebesar 5,90\%, faktor regret aversion, overconfidence, loss aversion, heuristic dan availability bias dapat memprediksi keputusan investasi emas masyarakat Kota Batam, sedangkan $94,10 \%$ dan dijelaskan oleh faktor lain diluar model penelitian. Table koefisien determinasi akan disajikan pada halaman berikut.

Tabel Hasil Uji Koefisien Determinasi

\begin{tabular}{ccc}
\hline Model & $\boldsymbol{R}$ Square & Adjusted $\boldsymbol{R}$ Square \\
\hline 1 & 0,059 & 0,037 \\
\hline \multirow{2}{*}{ Sumber : Data primer diolah (2019) }
\end{tabular}

\section{SIMPULAN}

Kesimpulannya adalah regret aversion menunjukkan adanya pengaruh signifikan positif terhadap variabel keputusan investasi dan konsisten terhadap penelitian sebelumnya yang pernah dilakukan oleh Velumoni (2017) dan Grover dan Singh (2015). overconfidence menunjukkan tidak adanya pengaruh signifikan terhadap variabel keputusan investasi, bertolak belakang dengan hasil penelitian Bakar dan Yi (2016), Qadri dan Shabbir (2014), Bashir et al. (2013), Antony dan Joseph (2017), Rostami dan Dehaghani (2015), Khan et al. (2017), Talha et al. (2015) dan Chitra dan Jayashree (2014). loss aversion menunjukkan adanya pengaruh signifikan negatif terhadap variabel keputusan investasi dan konsisten terhadap penelitian dilakukan oleh Bashir et al. (2013) dan Talha et al. (2015). Heuristic menunjukkan tidak adanya pengaruh terhadap keputusan investasi emas, bertolak belakang dengan penelitian yang dilakukan oleh Charles dan Kasilingam (2016), Kimeu et al. (2016) dan Farooq et al. (2015). Demikian juga dengan availability bias tidak berpengaruh terhadap keputusan investasi emas pada masyarakat Kota Batam, bertolak belakang dengan penelitian Bakar dan Yi (2016) dan Sadi et al. (2010).

\section{Keterbatasan}

Jumlah responden yang terkumpul hanya sedikit, dan mengakibatkan data penelitian yang didapatkan belum tentu mencerminkan keadaan yang sebenarnya, dengan objek penelitian yang dilakukan hanya pada masyarakat kota Batam saja, sehingga data yang diperoleh belum tentu mencerminkan keadaan yang sama seperti di kota Batam.

\section{DAFTAR PUSTAKA}

Aruna, P., \& Rajashekar, H. (2016). Factors Influencing Investment Decisions of Retail Investors- A Descriptive Study. International Journal of Business and Management Invention, 5(12), 6-9.

Awais, M., Laber, M. F., Rasheed, N., \& Khursheed, A. (2016). Impact of Financial Literacy and Investment Experience on Risk Tolerance and Investment Decisions: Empirical Evidence from Pakistan Mustabsar. International Journal of Economics and Financial Issues, 6(1), 73-79.

Bachdar, S. (2018). Orang Indonesia Lebih Senang Investasi Emas Ketimbang Saham. Retrieved February 9, 2018, from http://marketeers.com/orangindonesia-lebih-senang-investasiemas-ketimbang-saham/\%0D\%0D.

Bakar, S., \& Yi, A. N. C. (2016). The Impact of Psychological Factors on Investors' Decision Making in Malaysian Stock Market: A Case of Klang Valley and Pahang. Procedia Economics and Finance, 35(October 2015), 319-328.

Bashir, T., Javed, A., Ali, U., Meer, U. I., \& Naseem, M. M. (2013). Empirical Testing of Heuristics Interrupting the Investor , S Rational Decision Making. European Scientific Journal, 9(28), 432-444.

Burn, H. A. (2018). Harga emas dari November 2017-September 2018. Retrieved from http://www.hargaindo.com/2018/05/h arga-emas-hari-ini-jumat-01-juni2018.html 
Charles, A., \& Kasilingam, R. (2016). Impact of Selected Behavioural Bias Factors on Investment Decisions of Equity Investors. ICTACT Journal on Management Studies, 2(2), 297-311.

Chitra, K., \& Jayashree, T. (2014). Does Demographic Profile Create a Difference in the Investor Behavior? The International Journal of Business \& Management, 2(7), 24 30.

Chopde, S., \& Kulkarni, N. (2017). Impact of Behavioral Biases on Investment Decisions of Individual Investors in Mumbai A sample study. International Conference On Emanations in Modern Technology and Engineering (ICEMTE-2017), 5(3), 74-77.

Farooq, A., Afzal, M. A., Sohail, P. D. N., \& Sajid, M. (2015). Factors Affecting Investment Decision Making: Evidence from Equity Fund Managers and Individual Investors in Pakistan. Journal of Basic and Applied Scientific Research, 5(8), 6269.

Grover, P., \& Singh, L. K. (2015). Study on Behavioural Factors Influencing Investment Decision in Real State: A Case Study of Udham Singh Nagar (Uttrakhand). International Journal of Engineering Technology, Management and Applied Sciences, 3(7), 150-158.

Islam, A. M., Rahman, I. M., \& Yousuf, S. (2015). Investors' Investment Decisions in Capital Market: Key Factors. Global Journal of Management and Business Research: $C$ Finance, 15(4).

Kengatharan, L., \& Kengatharan, N. (2014). The Influence of Behavioral Factors in Making Investment Decisions and Performance: Study on Investors of Colombo Stock Exchange, Sri Lanka. Asian Journal of Finance \& Accounting, 6(1), 1-23.

Khaira, F. R., \& Khaira, F. A. (2016). The Influence of Education and
Experience Toward Investment Decision With Moderated By Financial Literacy. Polish Journal of Management Studies, 14(2), 51-60.

Khan, A. R., Azeem, M., \& Sarwar, S. (2017). Impact of Overconfidence and Loss Aversion Biases on Investment Decision: Moderating Role of Risk Perception. International Journal of Transformation in Accounting, Auditing, \& Taxation, 1(1), 1-12.

Khan, M. Z. U. (2015). Impact of Availability Bias and Loss Aversion Bias on Investment Decision Making , Moderating Role of Risk Perception. Journal of Research in Business Management, 1(2), 1-12.

Kimeu, C. N., Anyango, W., \& PHD, G. R. (2016). Behavioural Factors Influencing Investment Decisions Among Individual Investors in Nairobi Securities Exchange. The Strategic Journal of Business \& Change Management, 3(4), 12431258.

Kumar, S., \& Goyal, N. (2015). Behavioural biases in investment decision making - a systematic literature review. Qualitative Research in Financial Markets, 7(1), 88-108.

Kumari, S. (2016). Understanding the Impact of Behavioral factors on the Individual Investors Financial Decision Making: A Review of Empirical Evidences, 5(1), 13-34.

Prakoswa, R. H. (2018). Pertumbuhan Ekonomi RI Kuartal II Tertinggi Dalam 5 Tahun. Retrieved August 6, 2018, from https://www.cnbcindonesia.com/new s/20180806113140-4-

27110/pertumbuhan-ekonomi-rikuartal-ii-tertinggi-dalam-5-tahun

Rostami, M., \& Dehaghani, Z. A. (2015). Impact of behavioral biases ( overconfidence, ambiguity-aversion and loss-aversion ) on investment making decision in Tehran Stock 
Exchange. Journal of Scientific Research and Development, 2(4), 6064.

Sarwar, A., \& Afaf, G. (2016). A comparison between psychological and economic factors affecting individual investor's decision-making behavior. Cogent Business and Management, 3(1).

Sukheja, G. M. (2016). The impact of Behavioral psychology in Individual Investment Decision-Making. Journal of Insurance and Financial Management, 1(3), 67-81.
Talha, M., Ramanakumar, K. P., \& Neelakantan, P. R. (2015). Investor Psychology and its Influence on Investment Decisions. MAGNT Research Report, 3(9), 1444-8939.

Velumoni, D. (2017). Analysis of prospect theory on equity investment decision making-A behavioural perspective. Indian Journal of Science Research, 14(1), 211-215.

Velumoni, D., \& Rau, S. . (2015). Factors Influencing Equity Investment Decision. International Business Management,9(6),1359-1362. 